\title{
The role of encapsulating peritoneal sclerosis for the graft dysfunction in kidney transplantation: a case report
}

\author{
Yi-Chou Hou', Yu-Hua Lin², Chun-Hou Liao², Kuo-Cheng Lu ${ }^{3}$ \\ ${ }^{1}$ Department of Internal Medicine, Cardinal Tien Hospital, New Taipei City, Taiwan \\ ${ }^{2}$ Department of Urology, Cardinal Tien Hospital, New Taipei City, Taiwan \\ ${ }^{3}$ Department of Nephrology, Taipei Tzu Chi Hospital, New Taipei City, Taiwan
}

Background: Among the complications within the renal transplantations, early or delayed graft dysfunction is important issue because of its predictive value for chronic graft loss. Encapsulated peritoneal sclerosis (EPS) is the fibrotic change of the peritoneum in peritoneal dialysis (PD) patients. The longer duration of PD treatment is related to the occurrence of the EPS. Based on the lacking understanding of the EPS and its effect on the graft, we would like to present a case with pre-transplantation EPS, which caused delayed graft function by persistent ascites drainage.

Methods: A 52-year-old female received maintained PD since 2010 due to diabetic nephropathy with end-stage renal disease. The patient received PD with the following regimen; $2.5 \%$ Dianeal $2 \mathrm{~L}$ with duration of 4 hours for each session. Pre-transplantation EPS was noted. On January 7, 2020, the patient received a living-unrelated renal transplant.

Results: One day after transplantation, the patient's serum creatinine was still $10 \mathrm{mg} / \mathrm{dL}$. Oliguria was noted. Persistent exudative drainage from peritoneal cavity was noted. The daily output was $1,000 \mathrm{~mL} /$ day. After intravenous fluid was given, serum creatinine regressed. The daily amount of dialysate output decreased at the same time. In August 2020, the follow-up computer tomography demonstrated the regression of encapsulated sclerotic change. Serum creatinine regressed to $1.3 \mathrm{mg} / \mathrm{dL}$.

Conclusions: EPS is an important complication during the treatment of PD therapy. Persistent abdominal fluid drainage by ascites by EPS is rare and is a neglected etiology for delayed graft function. Further focus on the pre-transplantation EPS is needed.

Corresponding author: Yi-Chou Hou

E-mail: athletics910@gmail.com

(c) The Korean Society for Transplantation

This is an Open Access article distributed under the terms of the Creative Commons Attribution Non-Commercial License (http://creativecommons.org/licenses/by-nc/4.0/) which permits unrestricted non-commercial use, distribution, and reproduction in any medium, provided the original work is properly cited. 